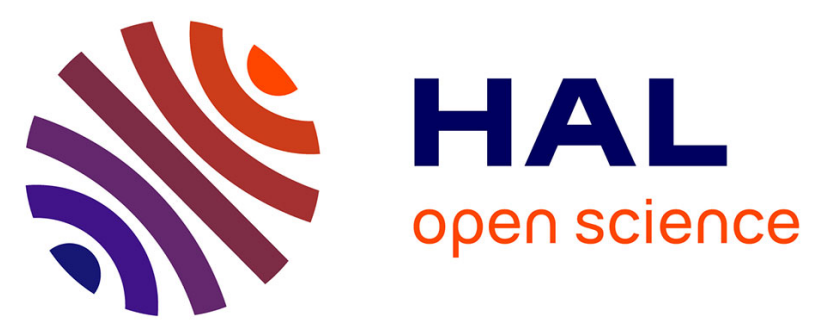

\title{
Intermittent hypoxia-induced delayed cardioprotection is mediated by PKC and triggered by p38 MAP kinase and Erk1/2.
}

Pauline C. Béguin, Elise Belaidi, Diane Godin-Ribuot, Patrick Lévy,

Christophe Ribuot

\section{To cite this version:}

Pauline C. Béguin, Elise Belaidi, Diane Godin-Ribuot, Patrick Lévy, Christophe Ribuot. Intermittent hypoxia-induced delayed cardioprotection is mediated by PKC and triggered by p38 MAP kinase and Erk1/2.. Journal of Molecular and Cellular Cardiology, 2007, 42 (2), pp.343-51. 10.1016/j.yjmcc.2006.11.008 . inserm-00126793

\section{HAL Id: inserm-00126793 https://www.hal.inserm.fr/inserm-00126793}

Submitted on 1 Feb 2007

HAL is a multi-disciplinary open access archive for the deposit and dissemination of scientific research documents, whether they are published or not. The documents may come from teaching and research institutions in France or abroad, or from public or private research centers.
L'archive ouverte pluridisciplinaire HAL, est destinée au dépôt et à la diffusion de documents scientifiques de niveau recherche, publiés ou non, émanant des établissements d'enseignement et de recherche français ou étrangers, des laboratoires publics ou privés. 
JMCC2335

Intermittent hypoxia-induced delayed cardioprotection is mediated by PKC and triggered by p38 MAP kinase and Erk1/2.

Pauline C. Béguin, Elise Belaidi, Diane Godin-Ribuot, Patrick Lévy, Christophe Ribuot.

Laboratoire HP2, Hypoxie Physio-Pathologie Respiratoire et Cardiovasculaire, EA3745, INSERM ERI 0017, Institut Jean Roget, BP 17038042 Grenoble Cedex 9, France.

Number of words: 5576

Abbreviated running head: intermittent hypoxia and cardioprotection

Please address correspondence to:

Professor Christophe Ribuot,

Laboratoire HP2, Hypoxie Physiopathologies Respiratoire et Cardiovasculaire,

EA3745, INSERM ERI 0017

Institut Jean Roget

BP 170

38042 GRENOBLE CEDEX 9, France.

Tel : 476637108 / Fax: 476637178

E-Mail: christophe.ribuot@ujf-grenoble.fr 
JMCC2335

\title{
Intermittent hypoxia-induced delayed cardioprotection is mediated by PKC and
}

\section{triggered by p38 MAP kinase and Erk1/2.}

Pauline C. Béguin, Elise Belaidi, Diane Godin-Ribuot, Patrick Lévy, Christophe Ribuot.

\begin{abstract}
\end{abstract}
Objective. We previously reported that acute intermittent hypoxia (IH) confers delayed cardioprotection against a prolonged ischemic insult in the rat, via the involvement of nitric oxide synthase and $\mathrm{K}_{\mathrm{ATP}}$ channels. In the present study, we investigated the role of protein kinase C (PKC), phosphatidylinositol-3-kinase (PI3K), stress activated p38 MAP kinase (MAPK) and extracellular signal regulated kinase (ERK1/2) using selective inhibitors of these pathways. Methods. Adult male rats were exposed to 1-min cycles of $\mathrm{IH}\left(10 \% \mathrm{O}_{2}, 40 \mathrm{sec}\right) /$ normoxia $\left(21 \% \mathrm{O}_{2}, 20 \mathrm{sec}\right)$ during $4 \mathrm{hrs}$ or to normoxic cycles. $24 \mathrm{hrs}$ later, isolated hearts were perfused in Langendorff mode and subjected to a 30-min global ischemia followed by 120 min of reperfusion. Results. Compared to normoxic conditions, IH significantly reduced infarct size $(22.2 \pm 2.4 \%$ vs $33.8 \pm 2.6 \%, \mathrm{p}<0.05)$, improved coronary flow and decreased the contracture at reperfusion. When administered before sustained ischemia, chelerythrine (a PKC inhibitor) abolished both the $\mathrm{IH}$-induced reduction in infarct size $(36.1 \pm 4.9 \%)$ and improvement in hemodynamic parameters. In contrast, chelerythrine administration $10 \mathrm{~min}$ before IH, did not modify the delayed cardioprotective response. Similarly, wortmannin (a PI3K inhibitor) administration 10 min before $\mathrm{IH}$ was unable to block the cardioprotective effects. However, administration of SB203580 (a p38 MAPK inhibitor) and PD98059 (an Erk1/2 inhibitor), 30 min before IH abolished its delayed infarct-sparing effect $(32.2 \pm 3.4 \%$ and $33.9 \pm 2.9 \%$ respectively). In addition, $24 \mathrm{hrs}$ after $\mathrm{IH}$, a significant increase in p38 MAPK and Erk1/2 phosphorylation was observed by Western blot. Conclusion. These results suggest that the delayed preconditioning induced by intermittent hypoxia does not involve the PI3K signalling pathway and that is mediated by PKC and triggered by p38 MAPK and Erk1/2. 
Key words: intermittent hypoxia, hypoxia/anoxia, infarction, preconditioning, protein kinase C, MAP kinase.

\section{Abbreviations}

$\mathrm{CF}$, coronary flow

Chel, chelerythrine

Dmso, dimethyl sulfoxide

HR, heart rate

I, infarct size

$\mathrm{IH}$, intermittent hypoxia

KH, Krebs-Henseleit buffer

LVDP, left ventricular developed pressure

LVEDP, left ventricular end-diastolic pressure

MAPK, mitogen-activated protein kinase

MEK, mitogen-activated protein kinase kinase

$\mathrm{N}$, normoxia

PI3K, phosphatidylinositol-3-kinase

PKC, protein kinase $\mathrm{C}$

RPP, rate pressure product

$\mathrm{V}$, ventricle size

WOT, wortmannin 


\section{Introduction}

Intermittent hypoxia (IH) is one of the major components of obstructive sleep apnea syndrome [1] [2]. It has been extensively demonstrated both in animals [3] and humans [4] that IH is a determinant of cardiovascular morbidity. Surprisingly, a decline in mortality rates with age has been observed in OSA patients [5], which suggests a possible cardiovascular protection by $\mathrm{IH}[6]$. There are several described differences between sustained hypoxia $(\mathrm{SH})$ and IH. Notably, it has been observed a differential gene activation under IH or SH [7]. We have thus studied the acute effects of a model mimicking the OSA consequences as previously described [8].

Hypoxic preconditioning (PC), like ischemic PC [9] can provide delayed protection against ischemia-reperfusion injury $[10,11]$. IH for $4 \mathrm{hrs}$ with $10 \% \mathrm{O}_{2}$ induces cardioprotection illustrated by a reduction of infarct size in isolated rat heart [8].

The cellular pathways and mechanisms involved in delayed ischemic PC are well documented. In particular, the first demonstration of a role for PKC in delayed PC, was from Yamashita and colleagues who demonstrated that staurosporine, a PKC inhibitor, could prevent in vitro the acquisition of this phenomenon in hypoxic preconditioned rat cardiomyocytes [12]. Subsequently, it was observed in the rabbit, that the delayed protection following ischemic PC is abolished in vivo by chelerythrine (Chel), another PKC inhibitor [13]. The first aim of the present study was to assess whether the IH-induced reduction in infarct size is mediated and/or triggered by PKC (i.e.: chelerythrine treatment before sustained ischemia or prior to hypoxic PC).

Recent studies have revealed that phosphatidylinositol 3-kinase/protein kinase B (PI3K-Akt) pathway is involved in delayed myocardial PC as a triggering actor. Notably, wortmannin (WOT), a PI3K inhibitor, administration before ischemic PC prevents the reduction in infarct size in the rabbit [14]. Moreover, in a mice model, WOT administration before pharmacological PC abolished its antiapoptotic effect [15]. Therefore, the second aim of this 
study was to test whether PI3K is involved in triggering the myocardial protection induced by $\mathrm{IH}$.

The mitogen-activated protein kinases (MAPK) mediate various cellular responses including proliferation, differentiation and adaptation to stress [16]. Two major MAP kinase families have been studied in the triggering phase of PC: the p38 MAPK and the extracellular signalregulated kinase $($ Erk1/2). The p38 MAPK signalling pathways has been shown to be implicated in both delayed ischemic [17] and pharmacological [18, 19] PC. Meanwhile, the Erk1/2 cascade has been involved in delayed hypoxic [20] and pharmacological PC [21]. Taken together, these findings led us to assess whether p38 MAPK and/or Erk1/2 activation participate to the IH-induced delayed cardioprotection. 


\section{Methods}

The investigation conforms to the Guide for the Care and Use of Laboratory Animals published by the US National Institutes of Health (NIH Publication No. 85-23, revised 1996).

Experiments were conducted on adult male Wistar rats (weight range 330-380 g) from Elevage Janvier (France) housed in controlled conditions and provided with standard rat chow.

\section{Intermittent hypoxia protocol}

Rats were exposed to intermittent hypoxia (IH) as previously described [8]. Briefly, rats were placed in Plexiglas chambers (length $28 \mathrm{~cm}$, diameter $10 \mathrm{~cm}$, volume 2.21 ). A timed solenoid valve was used to distribute nitrogen and air to each chamber. IH chambers were flushed with an air-nitrogen mixture for $40 \mathrm{sec}$ to achieve hypoxia $\left(10 \% \mathrm{O}_{2}\right)$ followed by $20 \mathrm{sec}$ of compressed air to restore normoxia $\left(21 \% \mathrm{O}_{2}\right)$. This 1-min cycle was repeated for $4 \mathrm{hrs}$. In parallel, compressed air at the same flow rate was distributed to sham chambers in order to submit sham animals to similar noise and airflow disturbances. The level of $\mathrm{O}_{2}$ in the chambers was controlled throughout the hypoxia protocol using a gas analyzer (model ML206, AD Instruments).

\section{Isolated rat heart preparation}

Twenty-four hours after $\mathrm{IH}$, the rats were anesthetized with $60 \mathrm{mg} / \mathrm{kg}$ i.p. sodium pentobarbital and treated with heparin $(500 \mathrm{UI} / \mathrm{kg}$, i.v.). Hearts were rapidly excised and briefly placed in cold $\left(4^{\circ} \mathrm{C}\right)$ Krebs-Henseleit $(\mathrm{KH})$ buffer before being mounted on the Langendorff apparatus via the aorta. The hearts were then retrogradely perfused at constant pressure $(75 \mathrm{mmHg})$, with $\mathrm{KH}$ buffer containing in $\mathrm{mM}$ : $\mathrm{NaCl} 118.0, \mathrm{KCl} 4.7, \mathrm{CaCl}_{2} 2.5$, $\mathrm{KH}_{2} \mathrm{PO}_{4}$ 1.2, $\mathrm{MgSO}_{4}$ 1.2, $\mathrm{NaHCO}_{3} 25.2$ and glucose 11.0. The perfusion medium was 
continuously gassed with $95 \% \mathrm{O}_{2}$ and $5 \% \mathrm{CO}_{2}$ and maintained at $37{ }^{\circ} \mathrm{C}$ and $\mathrm{pH} 7.4$ as previously described [8]. A water-filled latex balloon (Hugo Sachs, ${ }^{\circ} 4$ ), connected to a pressure transducer, was inserted into the left ventricular cavity via the left atrium for pressure recording. Left ventricular end-diastolic pressure (LVEDP) was adjusted between 5-10 mmHg. Myocardial temperature was measured by a thermoprobe inserted into the left atrium and was maintained constant at $37^{\circ} \mathrm{C}$. After $20 \mathrm{~min}$ of stabilization, no-flow global ischemia was induced by stopping the perfusion for $30 \mathrm{~min}$. The hearts were kept at constant humidity and temperature $\left(37^{\circ} \mathrm{C}\right)$ throughout ischemia and were thereafter reperfused for $120 \mathrm{~min}$. Coronary flow $(\mathrm{CF})$, expressed in $\mathrm{ml} / \mathrm{min} / \mathrm{g}$, was measured periodically during the ischemiareperfusion procedure, by collecting the effluent. Heart rate (HR), LVEDP, left ventricular developed pressure $($ LVDP $=$ difference between left ventricular systolic pressure and LVEDP) and dP/dt max (maximal rate of left ventricular pressure rise) were recorded continuously (PC Lab 4S, AD Instruments).

\section{Treatment groups}

Twenty-four hours prior to global ischemia-reperfusion, all rats were submitted to either normoxia $\left(\mathrm{N}, 21 \% \mathrm{O}_{2}\right)$ or intermittent hypoxia $\left(\mathrm{IH}, 10 \% \mathrm{O}_{2}\right)$ during $4 \mathrm{hrs}$, and randomised into one of 16 groups (Figure 1):

Groups $\mathrm{N}(\mathrm{n}=8)$ and IH (n=8) were only submitted to normoxic or IH exposure.

Groups N Chel1 ( $n=7)$ and IH Chel1 (n=7) were infused with chelerythrine $5 \mu \mathrm{M}$ [23], 10 min before ischemia.

Groups N dmso 10 (n=7), IH dmso 10 (n=9), N WOT (n=9), IH WOT (n=7), N Chel2 (n=9) and IH Chel2 (n=8), were injected (i.p.) with dmso $1 \%$, wortmannin $15 \mu \mathrm{g} / \mathrm{kg}$ [24] and chelerythrine $5 \mathrm{mg} / \mathrm{kg}$ [25] respectively, $10 \mathrm{~min}$ prior to $\mathrm{N}$ or $\mathrm{IH}$. 
Groups N dmso $30(n=7)$, IH dmso $30(n=8)$, N SB (n=8), IH SB (n=8), N PD (n=8) and IH PD (n=8), were injected (i.p.) with dmso 1\%, SB203580 $1 \mathrm{mg} / \mathrm{kg}$ [21] and PD98059 0,5 $\mathrm{mg} / \mathrm{kg}[18]$ respectively, $30 \mathrm{~min}$ prior to $\mathrm{N}$ or $\mathrm{IH}$.

\section{Infarct size}

At the end of the ischemia-reperfusion protocol, the atria were removed and the hearts were frozen at $-20^{\circ} \mathrm{C}$ for $10 \mathrm{~min}$. They were then cut into $2-\mathrm{mm}$ transverse sections from apex to base (6-7 slices/heart). Once thawed, the slices were incubated at $37^{\circ} \mathrm{C}$ with $1 \%$ triphenyltetrazolium chloride in phosphate buffer $(\mathrm{pH} 7.4)$ for $10 \mathrm{~min}$, fixed in $10 \%$ formaldehyde solution and photographed. Areas of infarcted tissue were measured using a computerized planimetric technique (Image Tool for Windows) and expressed as a percentage of total ventricular area (I/V).

\section{Western blotting}

To determine whether hypoxic PC was associated with an activation of Akt, p38 and Erk1/2 MAP kinases, hearts from additional animals ( $\mathrm{n}=4$ in each group) submitted to normoxia or IH were harvested 24 hrs later as described above. Hearts were homogenized in lysis buffer and centrifugated at $13000 \mathrm{rpm}$ for 20 minutes to remove nuclei and debris. The supernatant was collected and protein concentration was determined by the Pierce assay (Perbio Science France, Bezons, France). Proteins were loaded at 50-70 $\mu \mathrm{g} / \mathrm{lane}$. Phosphorylated states of Akt (phospho Akt; Ser 473), p38 MAPK (phospho p38; Thr180/Tyr182) and Erk1/2 (phosphoErk; Thr202/Tyr204) as well as total levels of Akt, p38 MAPK, Erk1/2 and GAPDH were analysed by $10 \%$ SDS/PAGE with antibodies from Cell Signaling Technology (Ozyme, Saint Quentin Yvelines, France) (except for GAPDH from Santa Cruz Technology, Tebu-Bio, Le Perray en Yvelines, France). Equal loading was confirmed with GAPDH, and levels of 
phosphorylated proteins were normalised to total protein levels assessed in the same samples and under the same conditions on separate membrane. Relative densitometry was computerized (Image J software).

\section{Exclusion criteria}

Only hearts with $\mathrm{CF} \leq 20 \mathrm{ml} / \mathrm{min} / \mathrm{g}$ and LVDP $>70 \mathrm{mmHg}$ at the end of the stabilization period were included in this study.

\section{Chemicals}

Chelerythrine, wortmannin and PD98059 were from Calbiochem (VWR International, Fontenay sous Bois, France), dmso from Sigma-Aldrich (Saint Quentin Fallavier, France) and SB203580 was synthesised by Dr A. Boumendjel (DPM, UMR 5063 UJF/CNRS, Université Grenoble I, France).

\section{Statistical analysis}

Hemodynamic and infarct size data are presented as mean \pm standard error of the mean (s.e.m.). Infarct size values and hemodynamic data were compared using two-way analyses of variance (ANOVA), with exposure and treatment corresponding to each factor. Post-hoc multiple comparisons were performed using Bonferroni tests. For blot analysis groups were compared using t-tests. Statistical significance was set at $\mathrm{p}<0.05$. 


\section{Results}

1- Intermittent hypoxia-induced myocardial preconditioning.

$\mathrm{IH}$ induced a delayed myocardial protection as shown by a smaller infarct-to-ventricle ratio $(22.2 \pm 2.4 \%$ in group $\mathrm{IH}$ vs $33.8 \pm 2.6 \%$ in group $\mathrm{N}, \mathrm{p}<0.05)$ (Figure $2 \mathrm{a}$ ) and an improvement in functional recovery at reperfusion illustrated by higher $\mathrm{CF}$ and smaller LVEDP values (Figure $2 \mathrm{~b}$ and Table 1). The stabilization values of hemodynamic parameters in $\mathrm{N}$ and $\mathrm{IH}$ groups are similar.

2- PKC is a mediator of $\mathrm{IH}$ preconditioning.

Infusion of chelerythrine $10 \mathrm{~min}$ prior to ischemia resulted in abolition of $\mathrm{IH}$-induced cardioprotection with no difference in infarct size $(36.1 \pm 4.9 \%$ in group IH Chel1 vs $39.4 \pm$ $5.5 \%$ in group N Chel1) (Figure 2a) nor in hemodynamic parameters (Figure 2b and Table 1) between hypoxic and normoxic groups. The stabilization values of hemodynamic parameters in $\mathrm{N}, \mathrm{IH}, \mathrm{N}$ Chel1 and IH Chel1 groups are similar.

3- PI3 kinase or PKC activation does not trigger IH preconditioning.

IH did not modify basal myocardial levels of Akt (Figure 3a bottom panel) compared to normoxic controls. The level of Akt phosphorylation in normoxic and hypoxic groups was similar. Wortmannin injection 10 min prior to $\mathrm{N}$ or IH induced a 1.5 fold decrease in Akt phosphorylation in both groups (Figure 3a). Wortmannin pretreatment did not modify the delayed protective effects on infarct size $(19.0 \pm 2.2 \%$ in group IH WOT vs $38.6 \pm 4.3 \%$ in group N WOT, p<0.05) (Figure 3b) and functional recovery upon reperfusion (Table 2).

Likewise, chelerythrine pretreatment did not prevent the cardioprotective effects on infarct size $(23.0 \pm 1.8 \%$ in group IH Chel 2 vs $35.0 \pm 3.4 \%$ in group $\mathrm{N}$ Chel2, $\mathrm{p}<0.05)$ (Figure $3 \mathrm{~b}$ ) and functional recovery (Table 3). Vehicle (dmso 1\%) injection $10 \mathrm{~min}$ prior to $\mathrm{N}$ or $\mathrm{IH}$ had 
no effect per se (Figure $3 \mathrm{~b}$ and Table 2). The stabilization values of hemodynamic parameters in $\mathrm{N}$ dmso 10, IH dmso 10, N Chel2, IH Chel2, N WOT and IH WOT groups are similar.

4- p38 MAP kinase and Erk1/2 activation are triggers of IH-preconditioning.

SB203580 as well as PD98059 injection $30 \mathrm{~min}$ prior to $\mathrm{IH}$ abolished the $\mathrm{IH}$-induced cardioprotective effects. Indeed, there was no difference in infarct size $(32.2 \pm 3.4 \%$ in group IH SB vs $33.5 \pm 2.5 \%$ in group N SB and $33.9 \pm 2.9 \%$ in group IH PD vs $26.8 \pm 3.9 \%$ in group N PD) (Figure 4) and in coronary flow upon reperfusion (Table 3) between hypoxic and normoxic animals. Vehicle (dmso 1\%) administration $30 \mathrm{~min}$ prior to $\mathrm{N}$ or IH had no effect per se (Figure 4 and Table 3). The stabilization values of hemodynamic parameters in $\mathrm{N}$ dmso 30, IH dmso 30, N SB, IH SB, N PD and IH PD groups are similar.

5- Phosphorylation of myocardial p38 MAPK and Erk1/2 after IH.

IH did not modify basal myocardial levels of p38 MAPK and Erk1/2 (Figures 5a and 6a, respectively) compared to normoxic control.

Twenty-four hours after IH, a 1.7 fold increase in p38 MAPK phosphorylation (Figure 5b) and a 1.5 fold increase in Erk1/2 phosphorylation (Figure 6b) were observed in the myocardium. 


\section{Discussion}

This study provides the first demonstration that $\mathrm{IH}$-induced delayed protection against myocardial infarction is triggered by $\mathrm{p} 38 \mathrm{MAPK}$ and Erk1/2 but not by PI3K and PKC. PKC, however, seems to play a role as a mediator of hypoxic PC. This is based on the observation that: 1) chelerythrine infusion before ischemia blocked the IH-induced cardioprotection, 2) wortmannin or chelerythrine injection prior to $\mathrm{IH}$ did not modify the cardioprotective response, 3) the MAP kinase inhibitor SB203580 and the MEK inhibitor PD98059, injected prior to $\mathrm{IH}$, blocked the $\mathrm{IH}$-induced cardioprotection and 4) a significant phosphorylation of both p38 MAPK and Erk1/2 was observed in the myocardium 24 hrs after IH.

In this study, we investigated the role of PKC in triggering and mediating IH-induced PC. We showed that IH-induced cardioprotection was abolished when chelerythrine was infused before ischemia. This is in accordance with other studies which have shown, using chelerythrine, a role for PKC in mediating delayed ischemic [13] and pharmacological [26] PC. However, the implication of other kinases can not be excluded since chelerythrine has been reported to affect some of them [27]. Furthermore, activation of PKC after ischemic PC is isoform selective. Notably, the epsilon isoform appears to be responsible for the development of delayed cardioprotection in the rabbit [28]. Thus assessment of the PKC isoform relevant to protection induced by $\mathrm{IH}$ should be of interest.

In a previous study [8], we suggested involvement of the ATP-sensitive potassium ( $\left.\mathrm{K}_{\mathrm{ATP}}\right)$ channel, as mediator of protection, in delayed hypoxic PC. Protein kinase-catalyzed phosphorylation is an important mechanism by which the activity of ion channels, including the $\mathrm{K}_{\mathrm{ATP}}$ channel, can be controlled [29]. There is evidence suggesting the importance of PKC in activating $\mathrm{K}_{\mathrm{ATP}}$ channels during the protective mechanism of delayed pharmacological PC [30]. Thus an interaction between PKC and $\mathrm{K}_{\mathrm{ATP}}$ in the IH-induced cardioprotection could be 
possible and this could be investigated in measuring mitochondrial matrix redox potential (an index of mitoK $\mathrm{ATP}_{\mathrm{AT}}$ channel activity) with and without a PKC inhibitor. In our previous study [8] we also demonstrated a role for NO synthase (NOS) in mediating IH-induced PC since a non specific inhibitor of NOS, L-NAME, abolished the delayed cardioprotection. We can suggest in the study presented here that PKC could play a role on NOS expression. Indeed, it is well-documented in ischemic or pharmacological PC, that activation of PKC-epsilon triggers a signalling cascade that leads to the binding of the transcription factor NF- $\mathrm{BB}$ to the inducible NOS (iNOS) promoter. This results in synthesis of new iNOS proteins, which leads to a preconditioned phenotype [31].

On the other hand, we showed that chelerythrine injection prior to IH did not modify IHinduced delayed cardioprotection. This is, to our knowledge, the first demonstration that the triggering phase of delayed PC is independent of PKC activation. However, this is consistent with previous studies focussing on early ischemic PC. The first one is by Przyklenk and colleagues who observed that PKC inhibition did not alter the infarct size reduction achieved by PC in the anesthetized open-chest dog [22]. Moreover, the work of Yang et al supports the idea that in rabbit heart, the trigger phase of PC does not require kinase activity, while the mediation phase is dependent on kinase phosphorylation [32].

The PI3K signalling pathway has been shown to confer protection against ischemiareperfusion injury via the activation of Akt [33]. Kis and colleagues have shown that WOT blocked delayed ischemic PC and prevented Akt phosphorylation in vivo in the rabbit [14]. In contrast, we observed that WOT, even if preventing Akt phosphorylation, did not block the $\mathrm{IH}$-induced PC. This discrepancy should be due to species differences, to the PC stimulus or to the WOT dosage used. Therefore, we can suggest that Akt phosphorylation is not involved in IH PC in the rat. This is also, to our knowledge, the first demonstration that the triggering 
phase of delayed PC is independent of PI3K activation. However, this is consistent with previous studies focussing on early pharmacological PC. Notably, the adenosine-induced PC was shown to be insensitive to wortmannin $[34,35]$.

Several studies have reported the implication of p38 MAPK in delayed pharmacological PC $[17,18]$. In accordance, we observed that SB203580, a p38 MAPK inhibitor, abolished the cardioprotection afforded by IH.

There is also evidence that hypoxia can activate p38 MAPK in several tissues including the heart $[36,37]$. Notably, p38 MAP kinase phosphorylation was reported 24 hrs after delayed pharmacological PC [38]. This is also confirmed in our study since we observed a myocardial activation of p38 MAPK 24 hrs after IH.

Since SB203580 has been reported to also inhibit the stress activated protein kinase, SAPK/JNK [39], we cannot rule out a role of this kinase in the PC conferred by IH. Moreover, controversy exists as to the beneficial-detrimental role of p38 MAPK in cardioprotection [40]. Indeed persistent activation of p38 MAPK during ischemia has been shown to be deleterious for cells $[41,42]$. This dual role may be explained by differential function of p38 subfamily members. Thus, it should be further investigated which p38 isoform is involved in the IH-induced delayed PC. Finally, the causal relationship between p38 MAPK phosphorylation and IH-induced cardioprotection should be assessed by studying the effect of SB203580 on p38 MAPK phosphorylation.

In contrast to the numerous reports involving p38 MAPK in delayed PC, there are few studies on Erk1/2, another member of the MAPK family. Two studies showed that PD98059 abolished delayed pharmacological PC $[18,21]$. Our study is the first to show that PD98059 blocked the IH-induced PC. Additionally, we observe an increase in Erk1/2 phosphorylation 24 hrs after IH. This result is in accordance with a study showing an increase in Erk1/2 
phosphorylation 18 hrs after hypoxia [35]. Like for p38 MAPK, the causal relationship between Erk1/2 phosphorylation and cardioprotection needs further investigation. Another limitation of our study is the use of inhibitors that are not fully specific (chelerythrine, SB203580), even if we used them at a concentration demonstrated in literature to have an effect in the rat.

One potential limitation of this study is that only one time point was chosen to examine the phosphorylation level of several protein kinases induced by IH. It would be important to examine the time course of phosphorylation/dephosphorylation of these protein kinases in the setting of IH PC and this is the subject of a future investigation.

In summary, this study shows that PKC, as a mediator, and p38 MAPK and Erk1/2, as triggers, participate to the $\mathrm{IH}$-induced delayed PC. In a putative linear pathway linking these various actors of hypoxic PC, we would thus expect PKC to be downstream from MAP kinases because treatment with the p38 MAPK and Erk1/2 inhibitors abolished cardioprotection when administered before IH and treatment with chelerythrine only abolished cardioprotection when given before the prolonged ischemic period. 


\section{Acknowledgements}

This work was supported by research grants from the Institut National de la Santé et de la Recherche Médicale (Inserm), the Région Rhône-Alpes and the Association Grenobloise des Insuffisants Respiratoires. P.C.B. and E.B. are recipients of doctoral fellowships from the Ministère de l'Enseignement Supérieur et de la Recherche.

We would like to thank Bruno Chapuis for the conception of the computer program controlling the hypoxic and normoxic cycles and Dr Ahcene Boumendjel for SB203580 synthesis. 


\section{References}

[1] Datta K, Bellacosa A, Chan TO, Tsichlis PN. Akt is a direct target of the phosphatidylinositol 3-kinase. Activation by growth factors, v-src and v-Ha-ras, in Sf9 and mammalian cells. J Biol Chem. 1996 Nov 29; 271(48): 30835-9.

[2] Neubauer JA. Invited review: Physiological and pathophysiological responses to intermittent hypoxia. J Appl Physiol. 2001 Apr; 90(4): 1593-9.

[3] Joyeux-Faure M, Stanke-Labesque F, Lefebvre B, Beguin P, Godin-Ribuot D, Ribuot $\mathrm{C}$, et al. Chronic intermittent hypoxia increases infarction in the isolated rat heart. $\mathrm{J}$ Appl Physiol. 2005 May; 98(5): 1691-6.

[4] Baguet JP, Hammer L, Levy P, Pierre H, Launois S, Mallion JM, et al. The severity of oxygen desaturation is predictive of carotid wall thickening and plaque occurrence. Chest. 2005 Nov; 128(5): 3407-12.

[5] Lavie P, Lavie L, Herer P. All-cause mortality in males with sleep apnoea syndrome: declining mortality rates with age. Eur Respir J. 2005 Mar; 25(3): 514-20.

[6] Lavie L, Lavie P. Ischemic preconditioning as a possible explanation for the age decline relative mortality in sleep apnea. Med Hypotheses. 2006; 66(6): 1069-73.

[7] Ryan S, Taylor CT, McNicholas WT. Selective activation of inflammatory pathways by intermittent hypoxia in obstructive sleep apnea syndrome. Circulation. 2005 Oct 25; 112(17): 2660-7.

[8] Beguin PC, Joyeux-Faure M, Godin-Ribuot D, Levy P, Ribuot C. Acute intermittent hypoxia improves rat myocardium tolerance to ischemia. J Appl Physiol. 2005 Sep; 99(3): 1064-9.

[9] Murry CE, Jennings RB, Reimer KA. Preconditioning with ischemia: a delay of lethal cell injury in ischemic myocardium. Circulation. 1986 Nov; 74(5): 1124-36. 
[10] Cai Z, Manalo DJ, Wei G, Rodriguez ER, Fox-Talbot K, Lu H, et al. Hearts from rodents exposed to intermittent hypoxia or erythropoietin are protected against ischemiareperfusion injury. Circulation. 2003 Jul 8; 108(1): 79-85.

[11] Xi L, Tekin D, Gursoy E, Salloum F, Levasseur JE, Kukreja RC. Evidence that NOS2 acts as a trigger and mediator of late preconditioning induced by acute systemic hypoxia. Am J Physiol Heart Circ Physiol. 2002; 283(1): H5-12.

[12] Yamashita N, Nishida M, Hoshida S, Kuzuya T, Hori M, Taniguchi N, et al. Induction of manganese superoxide dismutase in rat cardiac myocytes increases tolerance to hypoxia 24 hours after preconditioning. J Clin Invest. 1994 Dec; 94(6): 2193-9.

[13] Baxter GF, Goma FM, Yellon DM. Involvement of protein kinase C in the delayed cytoprotection following sublethal ischaemia in rabbit myocardium. Br J Pharmacol. 1995 May; 115(2): 222-4.

[14] Kis A, Yellon DM, Baxter GF. Second window of protection following myocardial preconditioning: an essential role for PI3 kinase and p70S6 kinase. J Mol Cell Cardiol. 2003 Sep; 35(9): 1063-71.

[15] Wang Y, Ahmad N, Kudo M, Ashraf M. Contribution of Akt and endothelial nitric oxide synthase to diazoxide-induced late preconditioning. Am J Physiol Heart Circ Physiol. 2004 Sep; 287(3): H1125-31.

[16] Sugden PH, Clerk A. "Stress-responsive" mitogen-activated protein kinases (c-Jun Nterminal kinases and p38 mitogen-activated protein kinases) in the myocardium. Circ Res. 1998 Aug 24; 83(4): 345-52.

[17] Carroll R, Yellon DM. Delayed cardioprotection in a human cardiomyocyte-derived cell line: the role of adenosine, p38MAP kinase and mitochondrial KATP. Basic Res Cardiol. 2000 Jun; 95(3): 243-9. 
[18] Lasley RD, Keith BJ, Kristo G, Yoshimura Y, Mentzer RM, Jr. Delayed adenosine A1 receptor preconditioning in rat myocardium is MAPK dependent but iNOS independent. Am J Physiol Heart Circ Physiol. 2005 Aug; 289(2): H785-91.

[19] Zhao TC, Hines DS, Kukreja RC. Adenosine-induced late preconditioning in mouse hearts: role of p38 MAP kinase and mitochondrial K(ATP) channels. Am J Physiol Heart Circ Physiol. 2001 Mar; 280(3): H1278-85.

[20] Gong KZ, Zhang ZG, Li AH, Huang YF, Bu P, Dong F, et al. ROS-mediated ERK activation in delayed protection from anoxic preconditioning in neonatal rat cardiomyocytes. Chin Med J (Engl). 2004 Mar; 117(3): 395-400.

[21] Fryer RM, Hsu AK, Gross GJ. ERK and p38 MAP kinase activation are components of opioid-induced delayed cardioprotection. Basic Res Cardiol. 2001 Apr; 96(2): 136-42.

[22] Przyklenk K, Sussman MA, Simkhovich BZ, Kloner RA. Does ischemic preconditioning trigger translocation of protein kinase $\mathrm{C}$ in the canine model? Circulation. 1995 Sep 15; 92(6): 1546-57.

[23] Hanlon PR, Fu P, Wright GL, Steenbergen C, Arcasoy MO, Murphy E. Mechanisms of erythropoietin-mediated cardioprotection during ischemia-reperfusion injury: role of protein kinase C and phosphatidylinositol 3-kinase signaling. Faseb J. 2005 Aug; 19(10): $1323-5$.

[24] Gross ER, Peart JN, Hsu AK, Auchampach JA, Gross GJ. Extending the cardioprotective window using a novel delta-opioid agonist fentanyl isothiocyanate via the PI3-kinase pathway. Am J Physiol Heart Circ Physiol. 2005 Jun; 288(6): H2744-9.

[25] Arnaud C, Joyeux-Faure M, Bottari S, Godin-Ribuot D, Ribuot C. New insight into the signalling pathways of heat stress-induced myocardial preconditioning: protein kinase Cepsilon translocation and heat shock protein 27 phosphorylation. Clin Exp Pharmacol Physiol. 2004 Mar; 31(3): 129-33. 
[26] Baxter GF, Mocanu MM, Yellon DM. Attenuation of myocardial ischaemic injury 24 h after diacylglycerol treatment in vivo. J Mol Cell Cardiol. 1997 Jul; 29(7): 1967-75.

[27] Yu R, Mandlekar S, Tan TH, Kong AN. Activation of p38 and c-Jun N-terminal kinase pathways and induction of apoptosis by chelerythrine do not require inhibition of protein kinase C. J Biol Chem. 2000 Mar 31; 275(13): 9612-9.

[28] Qiu Y, Ping P, Tang XL, Manchikalapudi S, Rizvi A, Zhang J, et al. Direct evidence that protein kinase $\mathrm{C}$ plays an essential role in the development of late preconditioning against myocardial stunning in conscious rabbits and that epsilon is the isoform involved. $\mathrm{J}$ Clin Invest. 1998 May 15; 101(10): 2182-98.

[29] Light PE, Bladen C, Winkfein RJ, Walsh MP, French RJ. Molecular basis of protein kinase C-induced activation of ATP-sensitive potassium channels. Proc Natl Acad Sci U S A. 2000 Aug 1; 97(16): 9058-63.

[30] Nayeem MA, Mustafa SJ. Mechanisms of delayed preconditioning with A1 adenosine receptor activation in porcine coronary smooth muscle cells. Pol J Pharmacol. 2002 Sep-Oct; 54(5): 443-53.

[31] Bolli R. Cardioprotective function of inducible nitric oxide synthase and role of nitric oxide in myocardial ischemia and preconditioning: an overview of a decade of research. $\mathrm{J}$ Mol Cell Cardiol. 2001 Nov; 33(11): 1897-918.

[32] Yang XM, Sato H, Downey JM, Cohen MV. Protection of ischemic preconditioning is dependent upon a critical timing sequence of protein kinase $\mathrm{C}$ activation. J Mol Cell Cardiol. 1997 Mar; 29(3): 991-9.

[33] Crisostomo PR, Wairiuko GM, Wang M, Tsai BM, Morrell ED, Meldrum DR. Preconditioning versus postconditioning: mechanisms and therapeutic potentials. J Am Coll Surg. 2006 May; 202(5): 797-812. 
[34] Qin Q, Downey JM, Cohen MV. Acetylcholine but not adenosine triggers preconditioning through PI3-kinase and a tyrosine kinase. Am J Physiol Heart Circ Physiol. 2003 Feb; 284(2): H727-34.

[35] Germack R, Dickenson JM. Adenosine triggers preconditioning through MEK/ERK1/2 signalling pathway during hypoxia/reoxygenation in neonatal rat cardiomyocytes. J Mol Cell Cardiol. 2005 Sep; 39(3): 429-42.

[36] Kulisz A, Chen N, Chandel NS, Shao Z, Schumacker PT. Mitochondrial ROS initiate phosphorylation of p38 MAP kinase during hypoxia in cardiomyocytes. Am J Physiol Lung Cell Mol Physiol. 2002 Jun; 282(6): L1324-9.

[37] Zheng M, Reynolds C, Jo SH, Wersto R, Han Q, Xiao RP. Intracellular acidosisactivated p38 MAPK signaling and its essential role in cardiomyocyte hypoxic injury. Faseb J. 2005 Jan; 19(1): 109-11.

[38] Dana A, Skarli M, Papakrivopoulou J, Yellon DM. Adenosine A(1) receptor induced delayed preconditioning in rabbits: induction of p38 mitogen-activated protein kinase activation and Hsp27 phosphorylation via a tyrosine kinase- and protein kinase C-dependent mechanism. Circ Res. 2000 May 12; 86(9): 989-97.

[39] Clerk A, Sugden PH. The p38-MAPK inhibitor, SB203580, inhibits cardiac stressactivated protein kinases/c-Jun N-terminal kinases (SAPKs/JNKs). FEBS Lett. 1998 Apr 10; 426(1): 93-6.

[40] Ping P, Murphy E. Role of p38 mitogen-activated protein kinases in preconditioning: a detrimental factor or a protective kinase? Circ Res. 2000 May 12; 86(9): 921-2.

[41] Saurin AT, Martin JL, Heads RJ, Foley C, Mockridge JW, Wright MJ, et al. The role of differential activation of p38-mitogen-activated protein kinase in preconditioned ventricular myocytes. Faseb J. 2000 Nov; 14(14): 2237-46.

[42] Tanno M, Bassi R, Gorog DA, Saurin AT, Jiang J, Heads RJ, et al. Diverse mechanisms of myocardial p38 mitogen-activated protein kinase activation: evidence for 


\section{JMCC2335}

MKK-independent activation by a TAB1-associated mechanism contributing to injury during myocardial ischemia. Circ Res. 2003 Aug 8; 93(3): 254-61. 


\section{Figure legends}

Figure 1. Experimental protocol. Rats were submitted to normoxia (N) or intermittent hypoxia (IH) during 4 hrs. Subsequently, all animals were allowed to recover for $24 \mathrm{hrs}$. Then, after a 20 min stabilization period, a 30-min no-flow global ischemia followed by a 120-min reperfusion was performed in vitro. Chelerythrine was infused 10 min before ischemia (Chel1). In other groups, wortmannin (WOT), chelerythrine (Chel2) and their vehicle (dmso 10) were injected intraperitoneally $10 \mathrm{~min}$ prior to normoxic or hypoxic stress. Finally, SB203580 (SB), PD98059 (PD) and their vehicle (dmso 30) were injected 30 min prior to stress.

Figure 2. a- Infarct size expressed as a percentage of ventricles (I/V) assessed after a no-flow global ischemia (30 min)-reperfusion (120 min) sequence, in groups exposed to normoxia (N) or intermittent hypoxia with $10 \% \mathrm{O}_{2}(\mathrm{IH})$ without and with chelerythrine infusion $10 \mathrm{~min}$ before ischemia (groups N Chel1 and IH Chel1). ${ }^{*} \mathrm{p}<0.05$, N.S: non significant using a twoway ANOVA. b- Effect of N, IH and chelerythrine infusion (Chel1) on coronary flow. After $20 \mathrm{~min}$ of stabilization, hearts were subjected to $30 \mathrm{~min}$ of no-flow global ischemia followed by $120 \mathrm{~min}$ of reperfusion. Coronary flow was collected at 5, 15, 30, 60, 90, $120 \mathrm{~min}$ of reperfusion. ${ }^{*} \mathrm{p}<0.05$ using a two-way ANOVA.

Figure 3. a- Representative Western blots demonstrating basal myocardial levels of Akt and phosphorylated Akt 24 hrs after IH in rats submitted to normoxia (N) or intermittent hypoxia (IH) and injected with dmso (dmso 10) or wortmannin (WOT). Density expressed in arbitrary units ( $\mathrm{n}=4$ per group). ${ }^{*} \mathrm{p}<0.05$ using a two-way ANOVA. b- Infarct size expressed as a percentage of ventricles (I/V) assessed after a no-flow global ischemia (30 min)-reperfusion (120 min) sequence, in hearts from rats injected with dmso (dmso 10), wortmannin (WOT) or chelerythrine (Chel2) 10 min prior to $\mathrm{N}$ or $\mathrm{IH} .{ }^{*} \mathrm{p}<0.05$ using a two-way ANOVA. 
Figure 4. Infarct size expressed as a percentage of ventricles (I/V) in hearts from rats injected with dmso (dmso 30), SB203580 (SB) or PD98059 (PD) 30 min prior to normoxia (N) or intermittent hypoxia (IH). ${ }^{*} \mathrm{p}<0.05$ using a two-way ANOVA.

Figure 5. a- Representative Western blots of basal myocardial levels of p38 MAP kinase (top panel) and phosphorylated p38 MAP kinase (bottom panel) 24 hrs after normoxia (N) or intermittent hypoxia (IH). b- Ratio of phosphorylated p38 MAP kinase over total p38 MAP kinase content in $\mathrm{N}$ and $\mathrm{IH}$ groups ( $\mathrm{n}=4$ per group). GAPDH demonstrates equal protein loading in experimental groups. Data are expressed as a percentage of normoxic control values. $* \mathrm{p}<0.05$ using a t-test.

Figure 6. a- Representative Western blots demonstrating basal myocardial levels of Erk1/2 and phosphorylated Erk1/2 24 hrs after normoxia (N) or intermittent hypoxia (IH). b- Ratio of phosphorylated Erk1/2 over total Erk1/2 content in $\mathrm{N}$ and $\mathrm{IH}$ groups ( $\mathrm{n}=4$ per group). GAPDH demonstrates equal protein loading in experimental groups. Data are expressed as a percentage of normoxic control values. ${ }^{*} \mathrm{p}<0.05$ using a t-test. 
Table 1. Hemodynamic parameters recorded in hearts from rats submitted 24 hrs earlier to normoxia $(\mathrm{N})$ or intermittent hypoxia $(\mathrm{IH})$ without and following chelerythrine infusion (Chel1) 10 min before ischemia.

\section{N IH $\quad$ N Chel1 IH Chel1}

\begin{tabular}{|c|c|c|c|c|c|}
\hline \multirow{3}{*}{$(\mathrm{ml} / \mathrm{min} / \mathrm{g})$} & $R 15$ & $6.0 \pm 0.2$ & $8.5 \pm 0.9$ & $4.4 \pm 0.3$ & $4.6 \pm 0.4$ \\
\hline & $R 60$ & $5.0 \pm 0.4$ & $7.5 \pm 0.9$ & $3.7 \pm 0.2$ & $3.8 \pm 0.4$ \\
\hline & $R 120$ & $4.3 \pm 0.3$ & $6.1 \pm 0.8$ & $2.8 \pm 0.3$ & $2.8 \pm 0.3$ \\
\hline LVEDP & \multicolumn{4}{|c|}{$*$} & \\
\hline \multirow[t]{3}{*}{$(\mathrm{mmHg})$} & $R 15$ & $71.9 \pm 5.4$ & $63.5 \pm 7.1$ & $65.3 \pm 4.7$ & $71.9 \pm 5.4$ \\
\hline & $R 60$ & $54.7 \pm 5.9$ & $45.7 \pm 6.2$ & $38.9 \pm 3.8$ & $54.7 \pm 5.9$ \\
\hline & $R 120$ & $47.0 \pm 5.4$ & $41.7 \pm 5.2$ & $34.3 \pm 3.7$ & $47.0 \pm 5.4$ \\
\hline$R P P$ & \multicolumn{4}{|c|}{$*$} & \\
\hline \multirow[t]{3}{*}{$(\mathrm{mmHg} / \mathrm{min})$} & $R 15$ & $11434 \pm 1911$ & $10331 \pm 2198$ & $3189 \pm 1336$ & $2249 \pm 749$ \\
\hline & $R 60$ & $13528 \pm 1737$ & $17136 \pm 1757$ & $8153 \pm 1842$ & $11426 \pm 1996$ \\
\hline & $R 120$ & $10803 \pm 1521$ & $13489 \pm 926$ & $6041 \pm 1181$ & $7019 \pm 916$ \\
\hline
\end{tabular}

CF - coronary flow, LVEDP - left ventricular end diastolic pressure, RPP - rate pressure product. R15, R 60 and R 120 after $15 \mathrm{~min}, 60 \mathrm{~min}$ and $120 \mathrm{~min}$ of reperfusion, respectively. Data are expressed as mean \pm s.e.m. ${ }^{*} \mathrm{p} \leq 0,05$. 
Table 2. Hemodynamic parameters recorded in hearts from rats pretreated 24 hrs earlier with dmso, chelerythrine or wortmannin 10 min prior to normoxia $(\mathrm{N})$ or intermittent hypoxia (IH).

N dmso 10 IH dmso 10 N WOT IH WOT N Chel2 IH Chel2

\begin{tabular}{|c|c|c|c|c|c|c|c|}
\hline \multirow{3}{*}{$(\mathrm{ml} / \mathrm{min} / \mathrm{g})$} & $R 15$ & $5.7 \pm 0.5$ & $6.3 \pm 0.3$ & $6.3 \pm 0.3$ & $8.0 \pm 0.6$ & $8.2 \pm 0.6$ & $8.0 \pm 0.7$ \\
\hline & $R 60$ & $5.0 \pm 0.6$ & $5.5 \pm 0.3$ & $4.8 \pm 0.2$ & $6.9 \pm 0.5$ & $6.6 \pm 0.5$ & $6.8 \pm 0.6$ \\
\hline & $R 120$ & $3.7 \pm 0.4$ & $4.4 \pm 0.1$ & $3.7 \pm 0.2$ & $5.2 \pm 0.4$ & $5.0 \pm 0.5$ & $5.0 \pm 0.5$ \\
\hline \multicolumn{2}{|l|}{ LVEDP } & \multicolumn{2}{|c|}{$*$} & \multicolumn{2}{|c|}{$*$} & & \\
\hline \multirow[t]{3}{*}{$(\mathrm{mmHg})$} & $R 15$ & $64.6 \pm 4.4$ & $62.6 \pm 2.5$ & $76.2 \pm 2.4$ & $64.1 \pm 3.0$ & $49.2 \pm 2.7$ & $48.4 \pm 5.7$ \\
\hline & $R 60$ & $47.0 \pm 4.9$ & $43.0 \pm 3.0$ & $66.5 \pm 7.4$ & $51.3 \pm 2.3$ & $36.7 \pm 2.3$ & $35.9 \pm 4.5$ \\
\hline & $R 120$ & $45.1 \pm 3.9$ & $40.0 \pm 2.9$ & $55.4 \pm 5.4$ & $44.5 \pm 1.5$ & $34.7 \pm 1.5$ & $34.0 \pm 3.4$ \\
\hline \multicolumn{4}{|l|}{$R P P$} & \multicolumn{2}{|c|}{ * } & & \\
\hline \multirow[t]{3}{*}{$(\mathrm{mmHg} / \mathrm{min})$} & $R 15$ & $6787 \pm 1210$ & $9987 \pm 1830$ & $8916 \pm 2038$ & $8452 \pm 2356$ & $14604 \pm 1987$ & $15684 \pm 3187$ \\
\hline & $R 60$ & $14645 \pm 2463$ & $15295 \pm 937$ & $8243 \pm 1671$ & $13337 \pm 1457$ & $17679 \pm 1610$ & $16723 \pm 2362$ \\
\hline & $R 120$ & $10701 \pm 1261$ & $11883 \pm 961$ & $6009 \pm 1046$ & $11604 \pm 1626$ & $13055 \pm 1325$ & $12253 \pm 1732$ \\
\hline
\end{tabular}

$\mathrm{CF}$ - coronary flow, LVEDP - left ventricular end diastolic pressure, RPP - rate pressure product. R15, R 60 and R 120 after $15 \mathrm{~min}, 60 \mathrm{~min}$ and $120 \mathrm{~min}$ of reperfusion, respectively. Data are expressed as mean \pm s.e.m. ${ }^{*} \mathrm{p} \leq 0,05$. 
Table 3. Hemodynamic parameters recorded in hearts from rats pretreated $24 \mathrm{hrs}$ earlier with dmso (dmso 30), SB203580 (SB) or PD98059 (PD) 30 min prior to normoxia (N) or intermittent hypoxia (IH).

N dmso 30 IH dmso $30 \quad$ N SB $\quad$ IH SB $\quad$ N PD $\quad$ IH PD

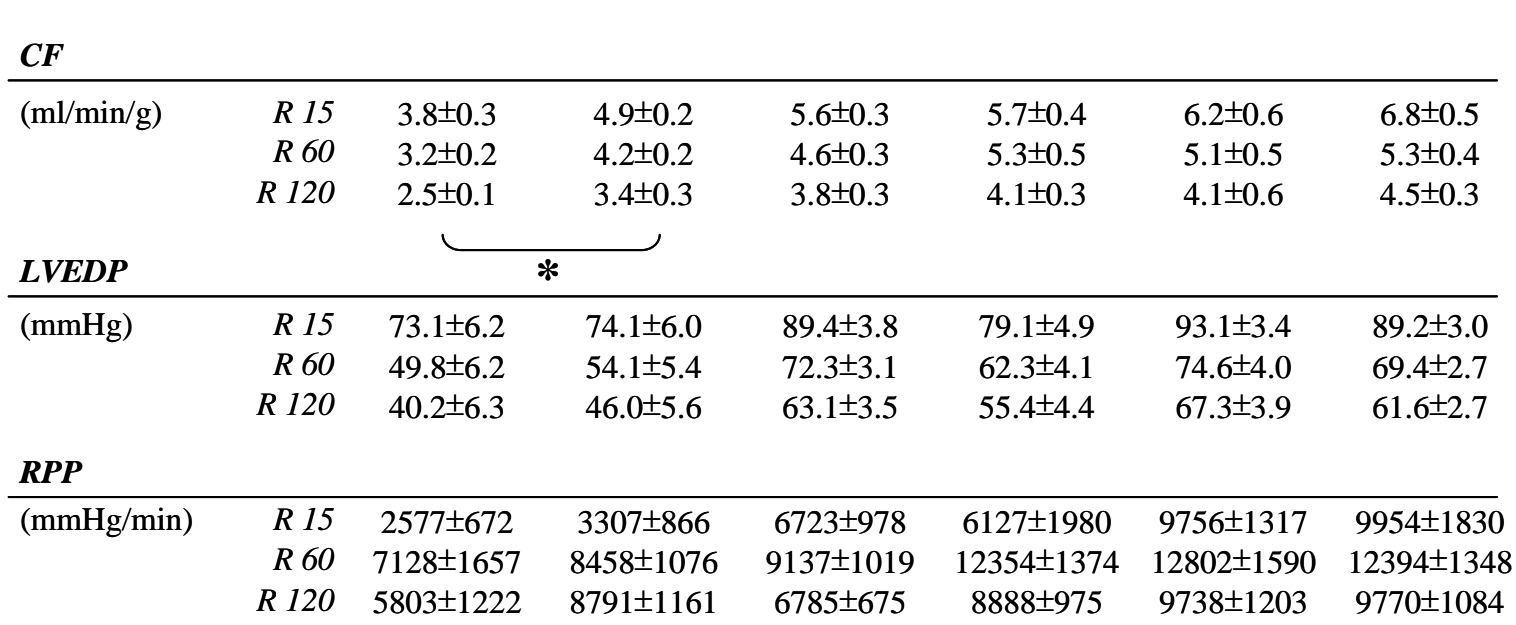

$\mathrm{CF}$ - coronary flow, LVEDP - left ventricular end diastolic pressure, RPP - rate pressure product. R15, R 60 and R 120 after $15 \mathrm{~min}, 60 \mathrm{~min}$ and $120 \mathrm{~min}$ of reperfusion, respectively. Data are expressed as mean \pm s.e.m. ${ }^{*} \mathrm{p} \leq 0,05$. 


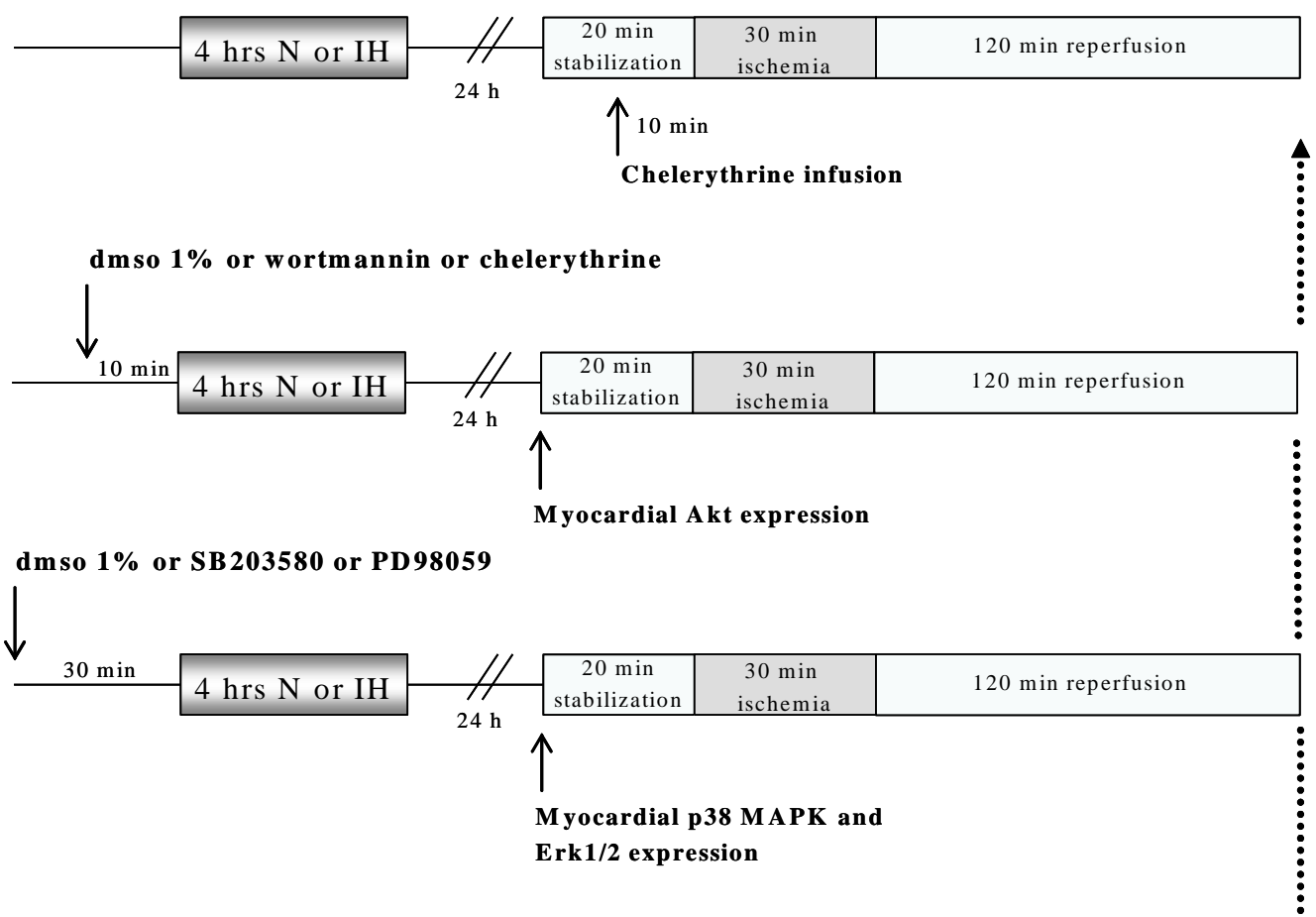

Groups:

$\mathbf{N}, \mathbf{I H}$,

N Chel1, IH Chel1

\section{Groups:}

N dmso 10, IH dmso 10

N WOT, IH WOT

N Chel2, IH Chel2

Infarct size

determination

\section{Groups:}

N dmso 30, IH dmso 30

N SB, IH SB

N PD, IH PD

\section{Figure 1.}


$2 a$

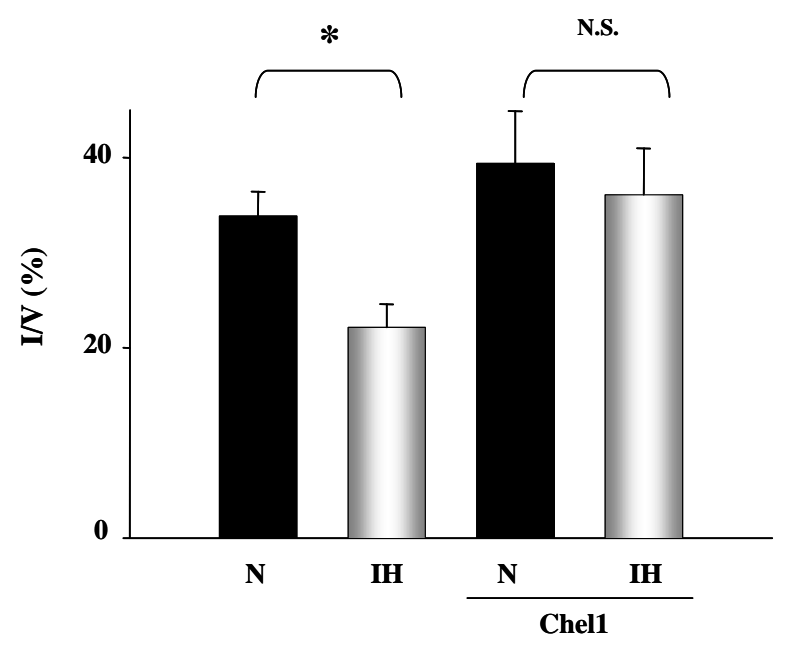

2b

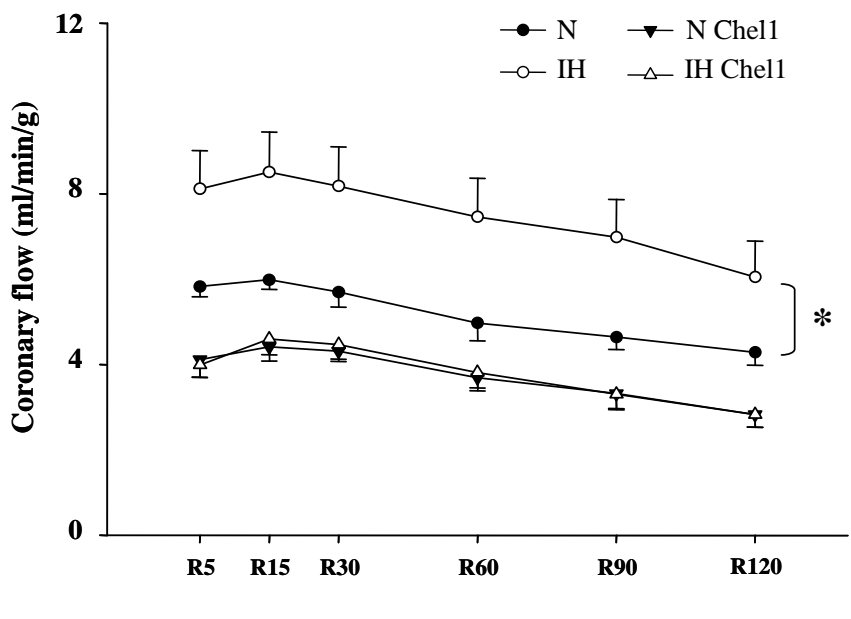

Figure 2. 
3a

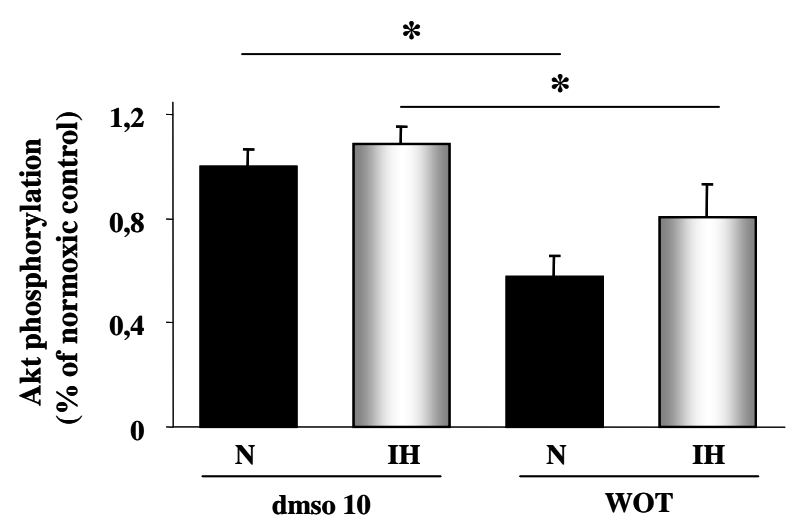

$3 b$

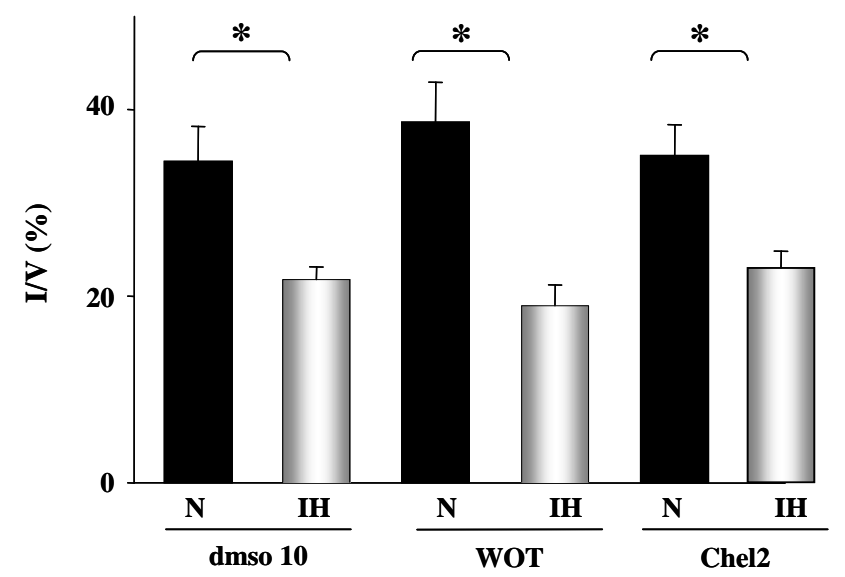

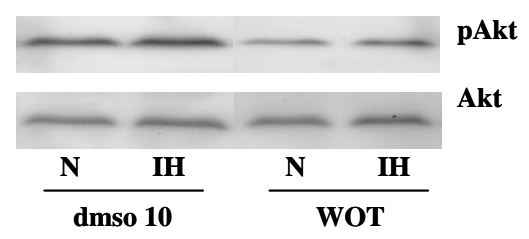

Figure 3. 
JMCC2335

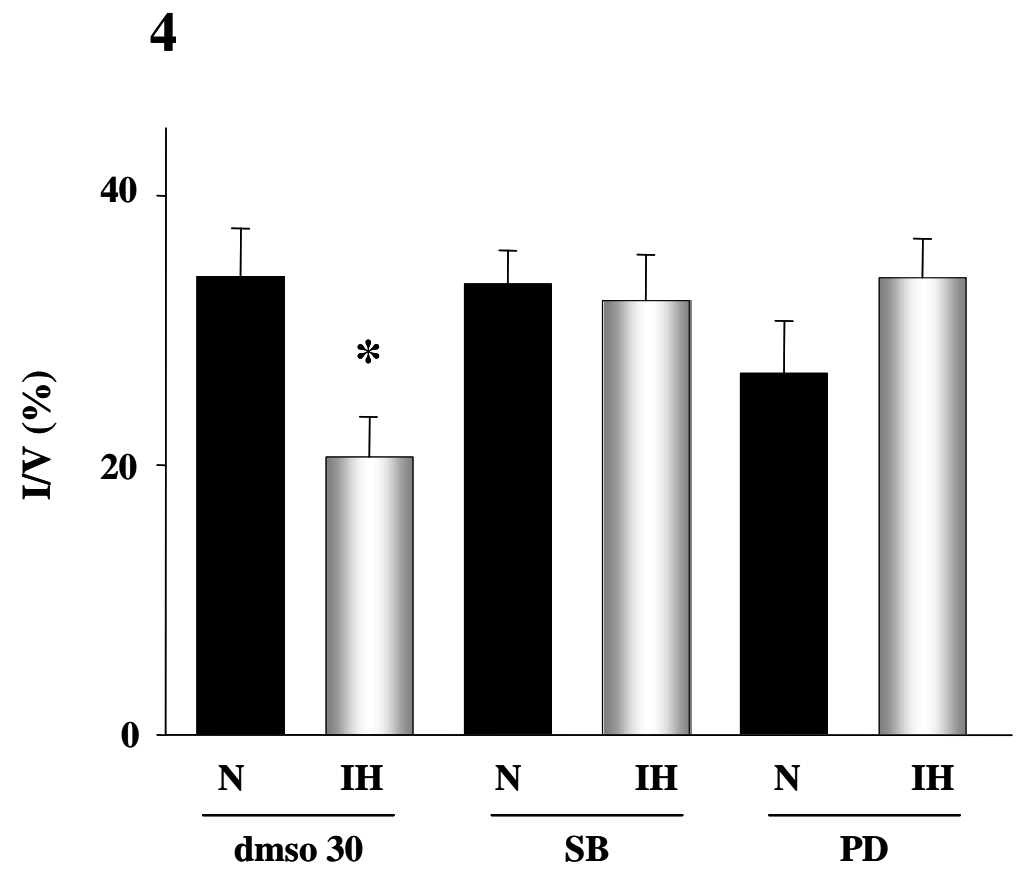

Figure 4. 
$5 a$
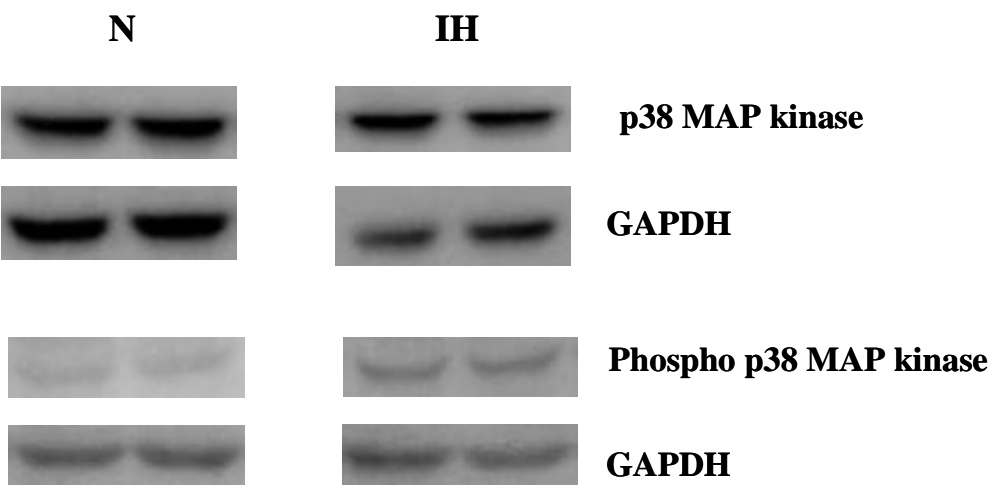

$5 b$

$*$

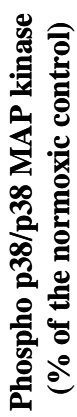

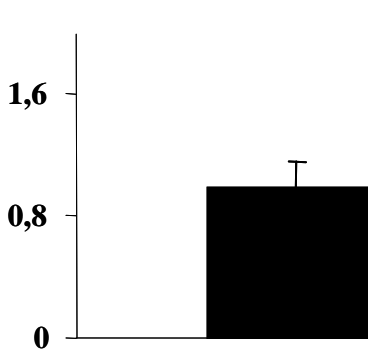

$\mathbf{N}$

IH

Figure 5. 
$6 a$
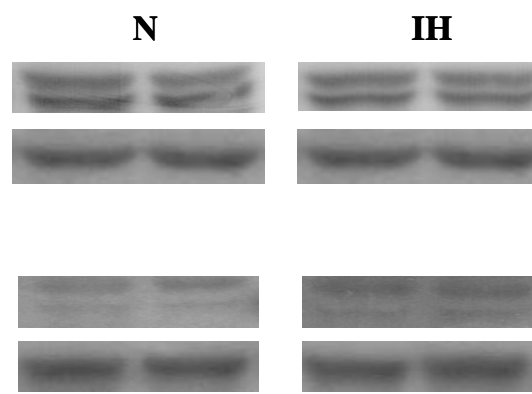

Erk1/2 MAP kinase

GAPDH

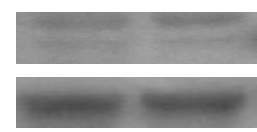

Phospho Erk1/2 MAP kinase

GAPDH

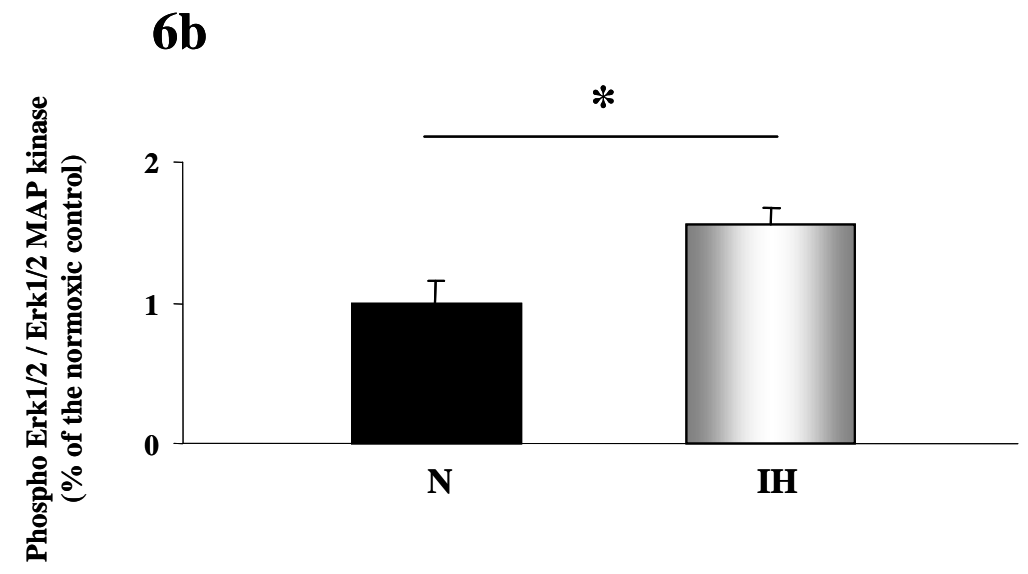

Figure 6. 